\title{
Retraction
}

\section{Retracted: Role of Surfactant in the Formation of Gold Nanoparticles in Aqueous Medium}

\section{Journal of Nanoparticles}

Received 16 December 2015; Accepted 16 December 2015

Copyright (C) 2015 Journal of Nanoparticles. This is an open access article distributed under the Creative Commons Attribution License, which permits unrestricted use, distribution, and reproduction in any medium, provided the original work is properly cited.

The paper titled "Role of Surfactant in the Formation of Gold Nanoparticles in Aqueous Medium" [1], published in Journal of Nanoparticles, has been retracted as it was accepted for publication on the basis of peer review reports that were submitted from fraudulent reviewer accounts.

In late 2014, a number of publishers discovered widespread abuse of the peer review process, including cases of identity theft and faked review reports. In July 2015, Hindawi concluded an extensive investigation into peer review fraud and identified a number of articles that had been accepted on the basis of fraudulent peer review reports. In accordance with the recommendations of the Committee on Publication Ethics (COPE), Hindawi sent these manuscripts for re-review using independent Editorial Board Members. Following this re-review process, this article has been retracted as it was deemed unsuitable for publication.

\section{References}

[1] A. Das, R. Chadha, N. Maiti, and S. Kapoor, "Role of surfactant in the formation of gold nanoparticles in aqueous medium," Journal of Nanoparticles, vol. 2014, Article ID 916429, 7 pages, 2014. 